\title{
Methods of digital marketing positioning in the global civil passenger aircraft market
}

\author{
Galina A. Kalugina
}

E-mail: kalugina@gmail.com

\author{
Anatoly V. Ryapukhin \\ E-mail: anatoliiruapukhin@yandex.ru
}

Moscow Aviation Institute (National Research University)

Address: 4, Volokolamskoe Shosse, Moscow 125993, Russia

\begin{abstract}
Under conditions of intense competition, the creation of new products and their promotion to the market requires marketing support. The central element of marketing innovation management is marketing positioning. In contrast to the methodological aspect, there is almost no procedural component of positioning in scientific works and publications. Moreover, due attention is not paid to the issues of market segmentation and the allocation of the competitive advantage of such hightech products as civil aircraft. This determines the relevance of the task of developing a procedure for marketing positioning within the framework of managing the product offer of the aircraft industry enterprises. From the standpoint of a systematic approach, the necessity of studying the adjacent air transportation market is reasonable, as well as the analysis of the correlation of its segmentation with the allocation of target segments of the aircraft market. When conducting a competitive analysis, we propose to consider the market position not only of certain types of civil aircraft, but also of aircraft families. Modeling marketing management shows the role of positioning in the processes of creating, manufacturing and operating aircraft. A distinctive feature of the procedure is the proposed stage of evaluating the effectiveness of the selected product position implementation, which allows us to analyze the feasibility of marketing decisions throughout the product life cycle. Special attention is paid to the issues of information support. The research results presented here reflect the specifics of the marketing activities of aviation industry enterprises and contribute to the development of the conceptual foundations of industrial marketing.
\end{abstract}

Key words: marketing positioning; marketing; segmentation; market research; aviation; aircraft.

Citation: Kalugina G.A., Ryapukhin A.V. (2021) Methods of digital marketing positioning in the global civil passenger aircraft market. Business Informatics, vol. 15, no 4, pp. 36-49. DOI: 10.17323/2587-814X.2021.4.36.49 


\section{Introduction}

The task of marketing positioning of goods is fundamental in managing the product range of a company. Formation of the marketing complex as a system of measures aimed at creation and promotion of competitive and commercially effective goods is based on determining and fixing in the minds of potential consumers of the target segment how the goods differ from the goods in competitive product offerings, i.e. competent marketing positioning of brand, individual model or product offering of the company as a whole. This problem is also relevant for aviation and industrial enterprises which produce such high-tech products as civil aircraft and promote them on the world market of aviation equipment.

There are many publications on passenger aviation and commerce, as well as many books on marketing touching on certain issues of positioning theory and practice. Some authoritative publications extensively cover the topic of marketing and economics in the aviation industry [1-3], but only partially address the problem of marketing positioning. In other scientific publications [4-6], there are the issues of development of the marketing management system, which allows us to study the market and make marketing decisions that increase competitiveness and market promotion of innovative high-tech products. The issues of the procedural component of the process of determining the position of the goods on the market are not given proper attention. Basically the procedural analysis is limited to the enlarged consideration of stages, such as a choice of ways of positioning, allocation of a system of positioning criteria, fixing the position of the goods among comparable competitive goods by means of marketing tools. It can be difficult to use theoretical developments in practice due to the impersonal nature of the object of positioning. Examples illustrating the procedural aspect of positioning most often refer to $\mathrm{B} 2 \mathrm{C}$ goods and do not reveal the peculiarities of the goods and the product market. There are fewer examples which characterize the process of marketing management in industrial markets. But it is the specifics of these markets that determine the complexity of the choice of competitive advantage, which should not be virtual, which is acceptable for consumer markets, where consumer preferences are often predetermined by the emotional impact of advertising, but are quite concrete. Industrial consumers must be able to verify the claimed position of the product against the possibilities of its effective operation. The process of accepting the product position by market actors requires appropriate procedures for detailed competitive analysis, and they should reflect the specifics of the product life cycle. As Hooley [7] noted, market positioning is, above all, a stage in the development of the marketing strategy of the company as a whole.

The question of information support and formation of databases for positioning of industrial goods is also timely.

The aim of this research is to model the procedure of marketing positioning for such hightech, science-intensive products as civil aviation equipment. The article presents the results of the study of the above-mentioned issues specifically for the market of civil aircraft.

If in most examples of market positioning the implementation of marketing management is based on the method of deduction, this article illustrates how the classical conceptual approach to determining the position of goods in the market by induction expands the possibilities of industry marketing.

\section{Methods of digital marketing positioning}

In the formation of the positioning procedure, solving the following tasks is supposed, aimed at a deeper and more detailed understanding of the possibilities of marketing management in high-tech industries: 
- defining principles of allocation of positioning stages;

- substantiation of the logical basis for structuring the process of positioning;

- formation of a system of requirements for the information necessary to implement the processes of research and decision-making at each stage, as well as critical analysis of information sources on the state of the market to form databases.

The fundamental principle of allocating the stages of the positioning procedure is the implementation of comprehensive and systematic approaches, which in solving the problem set involves a comprehensive analysis of factors reflecting the specifics of the product and its operation by the consumer (airlines) in a dynamically changing environment. In this regard, the procedure should consist of a greater number of stages aimed at solving the problems faced by the manufacturer of civil aircraft than we find in the positioning of consumer goods. Accordingly, more detailed elaboration of individual issues is also required when comparing the positioning of goods from the point of view of their operation.

Each stage must represent a finished action and be aimed at obtaining a result which can be evaluated quantitatively using formal indicators or qualitatively on the basis of individual or collective expertise.

When considering the issue of logical structuring of the decision-making process by the aircraft manufacturer on the declared position of its product, the analysis of a large number of variants of the problem solution with changing factors is assumed. All of this will allow us to evaluate the effectiveness of positioning with different combinations of segmentation criteria, attributes of building perception maps, etc. Thus, the procedure should be iterative. All stages should be interconnected logically so that each subsequent stage required solving the problems of the previous stage.
At the same time, the procedure must be interactive, which implies that there are stages of automated calculation, obtaining and processing of information and stages of human decision-making. This requirement is due to the need to consider a large number of options for combining attributes for different markets when building perception maps, as well as to choose the best method of positioning out of the available alternatives. Because of the long life cycle of such a product as civil passenger aircraft, we have to deal with the possibility of further repositioning, which also involves a large amount of analytical work.

In a view of the above, the procedure for positioning civil passenger aircraft can be shown as follows (Figure 1).

When considering the issue of information support of the positioning procedure, the fundamental condition is compliance with the information requirements:

- it must be from reliable sources;

- it must be available to market participants.

Table 1 presents an information map of databases required to implement the process of digital modeling of marketing positioning as a part of the management of civil aircraft creation and development.

\section{Results of industry research}

We consider in detail the implementation of the procedure of positioning aircraft manufacturers' products on the example of modern civil passenger aircraft.

\subsection{Study of the external environment}

The primary task is the study of the external environment of the aircraft-industrial enterprise and consumer segmentation, which corresponds to the stage 1 , in which the research of economic, political, socio-demographic, 


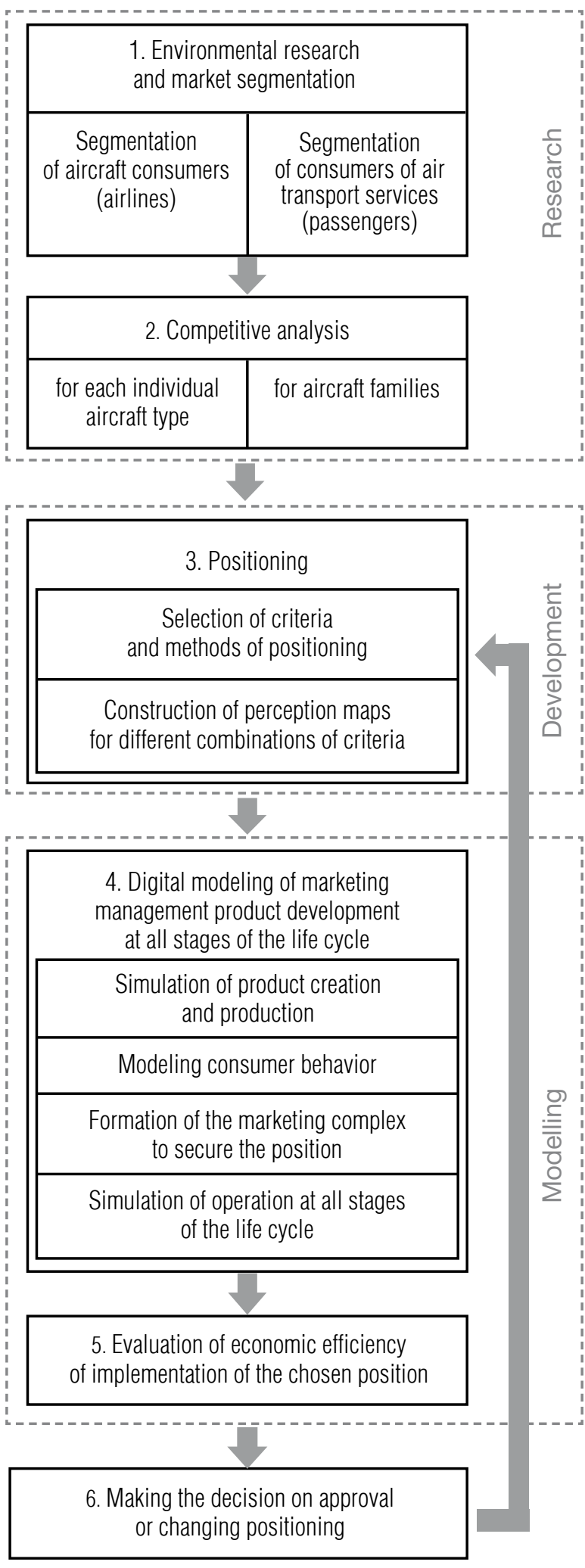

Fig. 1. Enlarged scheme of the marketing positioning procedure within the framework of modeling product creation environmental and other factors affecting the ability to promote and sell products, as well as market analysis from the perspective of the marketing environment, followed by consumer segmentation. At this stage it is possible to distinguish two directions which are interconnected with each other.

The process of market research of aviation equipment is one of the key processes, the main purpose of which is the analysis of market conditions and forecast of long-term trends of supply and demand for aviation equipment for a period of up to 30 years, which is conditioned by the long life cycle of the product. At the same time, it is necessary to simulate the main prospective changes in the composition of the aircraft fleet both in the whole world and for individual regions, countries and airlines. The forecast should reflect the flight-technical, economic and operational characteristics of all types and classes of aircraft.

To solve this problem, one should create a database of the world aircraft fleet, which contains comprehensive information on passenger aircraft: model, type and manufacturer of aircraft, date of manufacture, status and history of operation, including the resource indicators of the airframe and power plant, maintenance history, owner and operator of the aircraft, configuration with basic flight and technical characteristics, estimated cost, etc. Additionally, a database of commercial aircraft orders, including information on realized, concluded and probable (option) contracts, is required. The study uses sorting, sampling, classification, decomposition and extrapolation methods.

Consideration of the related market of air transportation is the second important direction of the study of the external environment. The main task is also the analysis of market conditions and forecasts of development trends, analysis of development of airlinesoperators of aircraft, as well as the study of the typology and behavior of end users - passengers. In the course of the study, it is necessary 
Database information map

Table 1.

\begin{tabular}{|c|c|c|}
\hline Stage/substage & $\begin{array}{l}\text { Type and method } \\
\text { of information collection }\end{array}$ & Source of information \\
\hline $\begin{array}{l}\text { External environment } \\
\text { research }\end{array}$ & $\begin{array}{l}\text { Statistical data } \\
\text { Expert evaluation }\end{array}$ & $\begin{array}{l}\text { World Bank, United Nations, Central Intelligence Agency, Eurostat, } \\
\text { Federal State Statistics Service (Russia), etc. }\end{array}$ \\
\hline $\begin{array}{l}\text { Segmentation } \\
\text { of consumers } \\
\text { (airlines) }\end{array}$ & $\begin{array}{l}\text { Statistical data } \\
\text { Interview/survey } \\
\text { Expert evaluation }\end{array}$ & $\begin{array}{l}\text { Federal Air Transport Agency, International Civil Aviation Organization } \\
\text { (ICAO), International Air Transport Association (IATA), Statistical } \\
\text { and analytical organizations (Cirium, CAPA, Airfinance, etc.) }\end{array}$ \\
\hline $\begin{array}{l}\text { Segmentation } \\
\text { of end users } \\
\text { (passengers) }\end{array}$ & $\begin{array}{l}\text { Statistical data } \\
\text { Interview/survey } \\
\text { Expert evaluation }\end{array}$ & ICAO, IATA, airlines, airports \\
\hline $\begin{array}{l}\text { Competitive } \\
\text { analysis }\end{array}$ & Statistical data & $\begin{array}{l}\text { Documentation of aircraft manufacturers, aviation authorities, } \\
\text { certification organizations, analytical agencies, etc. }\end{array}$ \\
\hline Positioning & $\begin{array}{l}\text { Calculated analytical data } \\
\text { Expert evaluation }\end{array}$ & Database on market research results \\
\hline Marketing modeling & $\begin{array}{l}\text { Calculated analytical data } \\
\text { Expert evaluation }\end{array}$ & Database on market research results \\
\hline $\begin{array}{l}\text { Assessment of } \\
\text { economic efficiency }\end{array}$ & $\begin{array}{l}\text { Calculated analytical data } \\
\text { Expert evaluation }\end{array}$ & Database on market research results \\
\hline $\begin{array}{l}\text { Making a decision } \\
\text { to approve or change } \\
\text { the position }\end{array}$ & $\begin{array}{l}\text { Calculated analytical data } \\
\text { Expert evaluation }\end{array}$ & Database on market research results \\
\hline
\end{tabular}

to use statistical databases containing data on the volume of air transportation in different perspectives, namely by routes, flights, capacity and passenger flows. Information will also be required on flights between airports with classification by aircraft type, operator, class of flights themselves, as well as financial indicators allowing for profitability and cost analysis in their performance. Such an extensive analysis serves as a basis for forecasting traffic volume trends with a detailed classification by class and type of aircraft, by operator and by geographical distribution.

Studies of secondary markets, such as railroads, automobile and other types of passenger transportation, are also conducted in addition. High-speed rail transport is becoming a significant competitor to air transportation, and on certain routes it has become equal to air transportation in terms of availability, speed, travel time and volume. As a rule, high-speed railroads are created on Russian routes with very high regular passenger traffic and cannot occupy the entire share of the local market. Typical examples are rail transportation in Europe, Japan, China, as well as in Russia on the Moscow - St.Petersburg route and other new destinations.

End user research is aimed at identifying the factors that determine trends in air travel and involves analysis of demographic and socioeconomic components at the level of a detailed study of the population of countries and regions of the world in the framework of the consumer behavior concept. At the same time, the issues of studying the lifestyle and economic situation of the population as preconditions for the change in effective demand for air trans- 
portation are relevant. It is also necessary to take into account the geographical features of regions and individual cities, the level of development of industry and tourism.

As a result of the study, it becomes possible to calculate and forecast the index of population mobility up to individual settlements, as well as to identify the correlation of the studied indicators and their impact on the projected volume of transportation with detail down to individual routes. The solution of the above tasks requires a large volume of statistical data on many quantitative and qualitative indicators. Correlation and regression analysis is appropriate to identify the relation between the factors and assess the degree of interdependence of the criteria selected for analysis, while the expert assessment is appropriate to determine the weighting parameters of the impact of input data on the final indicators.

In the study of the external environment, consideration of the global political situation is very important. Despite the overall globalization of developed countries, which are the main and in many segments the only producers of aviation equipment, one can observe not only examples of political and economic sanctions against developing countries and third world countries (such as the ban on the supply of Western aircraft to Iran and Cuba), but also an open struggle between developed countries, using various political, customs and economic barriers in the aviation equipment and air transportation market. The most attractive and capacious United States market, where conflicts between regional aircraft producers (Embraer, Bombardier) [8, 9] and long-haul aircraft producers (Airbus, Boeing) $[10,11]$ periodically escalate, is a vivid example of competition with political and economic methods in the segment of regional and long-haul passenger aircraft. The study requires not only factual data on existing constraints or barriers, but also expert analysis and forecasting of developments in the field of politics and economics.

\subsection{Consumer segmentation}

One part of the study of the external environment is customer segmentation. When considering civilian passenger aircraft as a B2B commodity, it is necessary to segment not only customers (i.e. airlines), but also the segmentation of end consumers - passengers, as the market for aircraft equipment and the market for passenger air transportation are closely linked. Airline market trends are directly reflected in aircraft market trends.

Segmentation of the markets of aviation equipment and air transportation involves the following tasks:

- formation of a database structure on the characteristics of airlines and passengers;

- collection of necessary information and filling the database;

- analysis of the characteristics and needs of potential buyers;

- selection of criteria for segmentation of consumers of the market of aviation equipment and air transportation market;

- implementation of market segmentation, taking into account the correlation between the markets of aircraft equipment and air transportation;

- clarification of boundaries of market segments of aircraft equipment, taking into account the related market of air transportation;

- selection of target segments of both markets.

Due to the fact that the product in question is high-tech and technically complex and belongs to the B2B market, it has a huge number of consumer characteristics analyzed by the customer in product selection, as well as considered by the manufacturer in segmentation and positioning. As Guzhva [12] noted, research objects related to $\mathrm{B} 2 \mathrm{~B}$ products require a deeper analytical approach in market research, 
competitive analysis and customer segmentation. As a part of the segmentation, one should create a multidimensional matrix, where each criterion under consideration forms a dimension consisting of a sequence of values. Figure 2 shows the conceptual model of the formation of two-dimensional segmentation matrices reflecting the relation between segments of the airline and aviation market. Each matrix has a multidimensional structure $(N=1, \ldots, i$; $M=1, \ldots, i i)$ with a large array of data $\left(N_{i}, M_{i i}\right)$. In practice, the formation of this matrix when selecting target segments is associated with the processing of a huge amount of information.

As a result of data processing, the target segments and groups of segments in multidimensional matrices should be identified, the correlation between segments of different matrices should be determined (Figure 2) and a characterization of each multidimensional segment should be given.

\subsection{Competitive analysis}

Competitive analysis, an enlarged conceptual model of which is presented in Figure 3, includes the study of functional, generic and subject competitors, which corresponds to stage 2 of the marketing positioning procedure. The analysis includes the study of consumer characteristics of services of functional and generic competitors, as they are necessary for further comparison (transportation parameters, price, etc.). When analyzing the subject competitors (similar passenger airplanes), the study of not only consumer but also techni-

\begin{tabular}{|c|c|c|c|c|c|}
\hline & & \multicolumn{4}{|c|}{ Segmentation of customers (airlines) according to the criterion $N_{1}, N_{2}, \ldots, N_{i}$} \\
\hline & & \multicolumn{4}{|c|}{ Criterion $N_{1}$. Ranges $D_{1}, D_{2}, \ldots, D_{j}$} \\
\hline & & $D_{1}$ & $D_{2}$ & $\cdots$ & $D_{j}$ \\
\hline \multirow{4}{*}{ 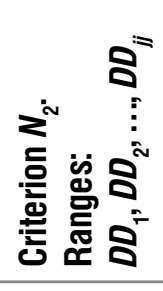 } & $D D_{1}$ & Segment 1,1 & Segment 2,1 & $\ldots$ & Segment $j, 1$ \\
\hline & $D D_{2}$ & Segment 1,2 & Segment 2,2 & $\ldots$ & Segment $j, 2$ \\
\hline & $\cdots$ & $\ldots$ & $\ldots$ & $\cdots$ & $\cdots$ \\
\hline & $D D_{i j}$ & Segment $1, j j$ & Segment 2,jj & $\ldots$ & Segment $j, j j$ \\
\hline & & \multicolumn{4}{|l|}{ 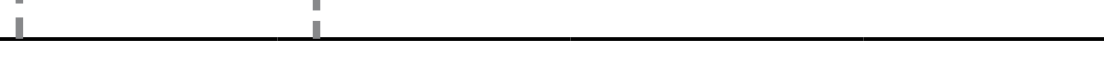 } \\
\hline & & \multicolumn{4}{|c|}{$\begin{array}{l}\text { Segmentation of end users (passangers) according } \\
\text { to the criterion } M_{1}, M_{2}, \ldots, M_{i i}\end{array}$} \\
\hline & & \multicolumn{4}{|c|}{ Criterion $M_{1}$. Ranges $E_{1}, E_{2}, \ldots, E_{q}$} \\
\hline & & $V \quad E_{1}$ & $E_{2}$ & $\cdots$ & $E_{q}$ \\
\hline \multirow{4}{*}{ 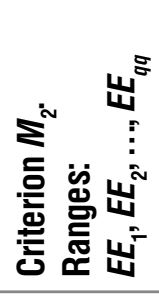 } & $E E_{1}$ & Segment 1,1 & Segment 2,1 & $\cdots$ & Segment $q, 1$ \\
\hline & $E E_{2}$ & Segment 1,2 & Segment 2,2 & $\cdots$ & Segment $q, 2$ \\
\hline & $\ldots$ & $\cdots$ & $\cdots$ & $\cdots$ & $\cdots$ \\
\hline & $E E_{q q}$ & Segment $1, q q$ & Segment2,qq & $\cdots$ & Segment $q, q q$ \\
\hline
\end{tabular}

Fig. 2. Correlation of customers' segmentation of aviation equipment (airlines) and consumers of air transportation (passengers) 
cal parameters is carried out for a more complete characterization of competitive products and forecast of their development. At the same time, not only airplanes, but their families are analyzed, with different types and modifications of airplanes of one type grouped into a family. The unification has higher consumer characteristics and allows coverage of a larger market segment. The topic of aircraft families is discussed in detail by Kalugina [13].

In the course of competitive analysis, a database of product characteristics is formed, their interrelation is determined, derived indicators are calculated as a ratio of initial indicators and parameter indicators which require more complex calculations (economic and operational characteristics) are singled out. According to the results of the analysis, the competitive options are compared with the designed aircraft by the entire set of parameters.

\subsection{Positioning an aircraft family}

The marketing positioning of a new aircraft or family of aircraft corresponds to stage 3 of the enlarged positioning procedure. Based on the results of environmental research and segmentation, using the characteristics of competitive products and the results of comparative analysis of aircraft and their families and taking into account the forecast of development for the coming 20-40 years, the choice of positioning criteria is made. The information model of the process of marketing positioning of airplanes is reflected in Figure 4.

Positioning criteria can be any consumer characteristics of the products that best reflect the competitive advantages of the aircraft from the point of view of consumers. The selected criteria are then combined into pairs to build perception maps. The perception map or positioning map is a graph that visually shows the positions of certain brands in terms of the most important product characteristics for the consumer. The map is built using two defining parameters as $X$ and $Y$-axes. The most common parameters for comparing products and building the brand perception map are the following: quality, price, safety, reliability and functional characteristics. The main advantage of the brand position visualization method with perception maps is that it is very easy to construct and interpret.

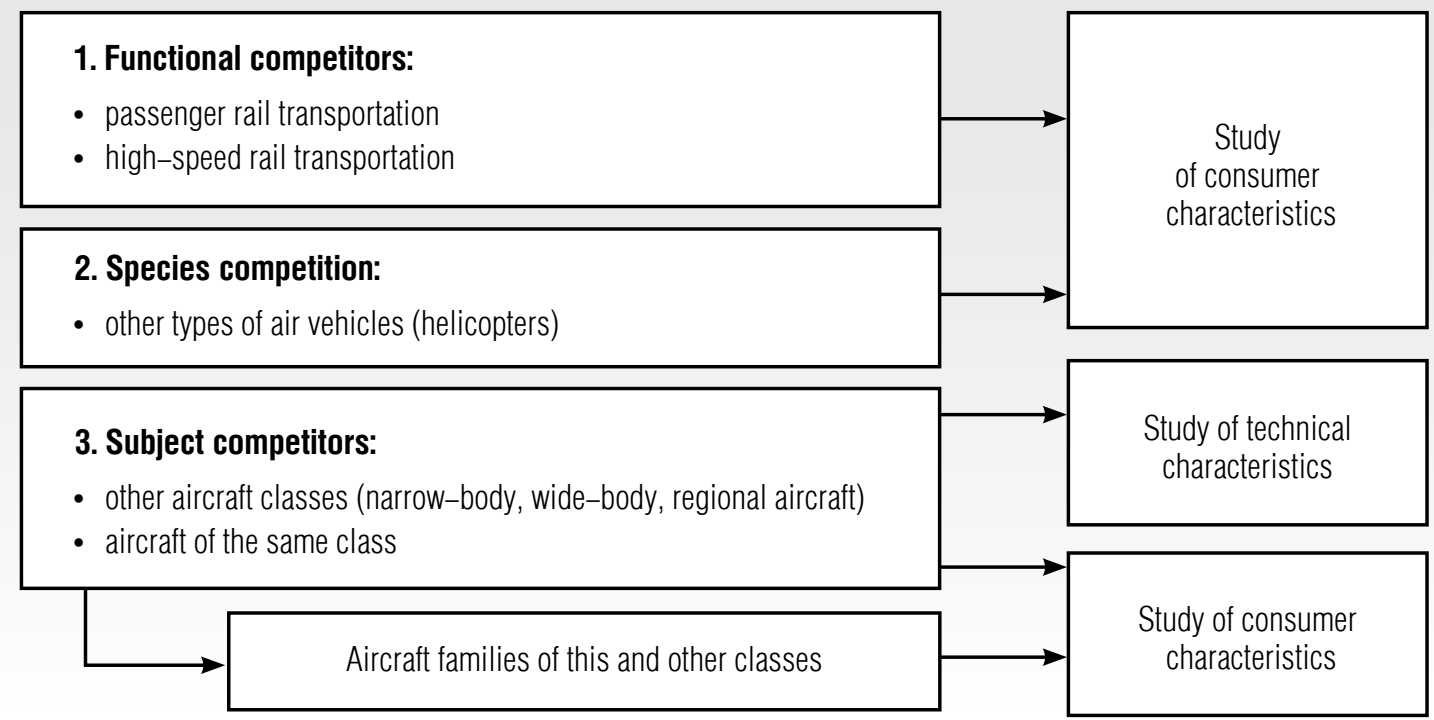

Fig. 3. Conceptual model of competitive analysis 


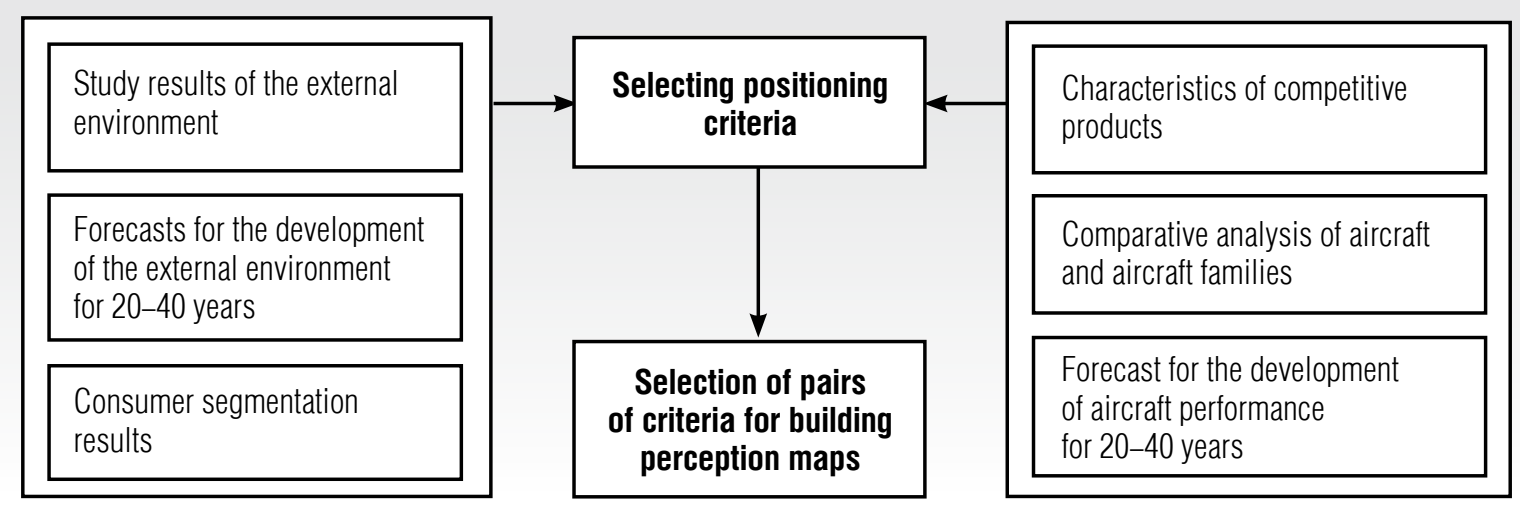

Fig. 4. Information model of aircraft marketing positioning

It is important to note that for perception maps even indicators in which products are inferior to competitors can be selected, in case:

- choice is due to the high correlation of the indicators of the selected pair;

- position of the product on the perception map is above the "line" of the market trend;

- position of the product is insignificantly inferior to "recognized" competitors in the market which are already a success;

- positioning on the perception map allows one to occupy a larger area than competitors when comparing aircraft families, which is one of the positioning objectives.

\subsection{Examples of perception maps}

Figure 5 shows a conditional example of a perception map to illustrate the marketing positioning of commercial aircraft according to the criteria of range (criterion 1) and passenger capacity of the aircraft (criterion 2).

The perception map identifies the positions of 15 aircraft, grouped by manufacturer and the families to which they belong. There are four manufacturers (A, B, C, D) with their families of aircraft $(1,2,3,4,5)$. The map shows a trend line, characterizing the average trend of dependence of criterion 2 on criterion 1 calculated on the basis of analysis of the characteristics of the aircraft on the market, and a corridor of deviation from the trend line of $-10 \%$ and $+10 \%$. The advantages and disadvantages of aircraft positioning are not considered for each aircraft separately by criterion 1 and 2, but by its location within the family and the manufacturer's product offering as a whole, as well as depending on the positions of competitors.

Positioning families, as opposed to positioning individual aircraft, enhances the ability to meet demand in more market segments, thereby improving the company's commercial performance.

Manufacturer A offers Family 1 and Family 2, thereby covering multiple market segments. Although Family 1 is inferior to its competitors, it is nevertheless in the trend of the market. Family 2 is noticeably above the trend line, which strengthens the position of Producer A.

Manufacturer B offers one Family 3, consisting of four aircraft. So, the family occupies more market segments than its competitors.

Manufacturer C offers one Family 4, which does not occupy as many market segments as Family 3, but outperforms it in criteria 1 and 2 .

Manufacturer D offers Family 5 consisting of only two aircraft. This family is below the trend 


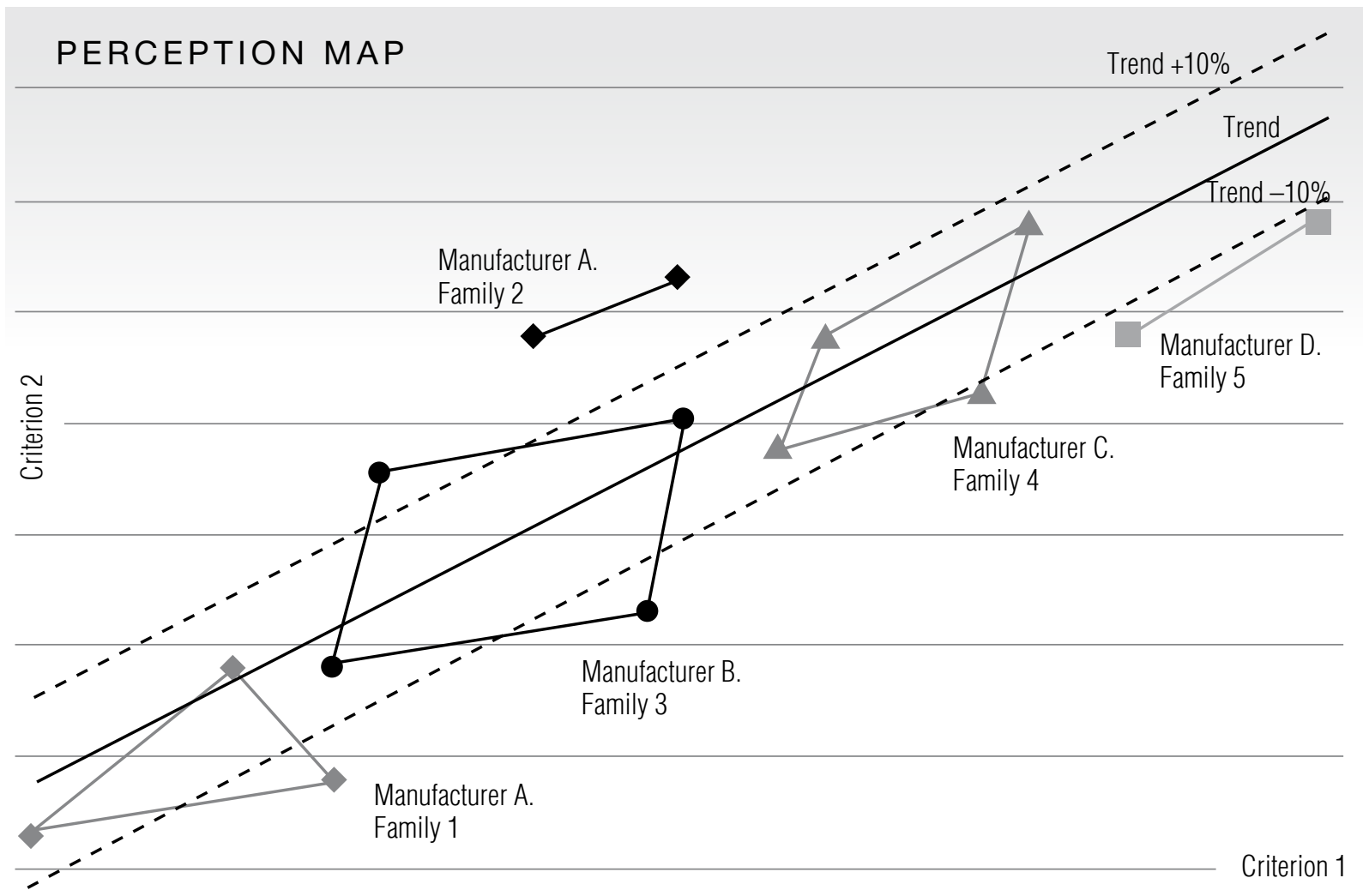

Fig. 5. Conditional example of a perception map

line, but it targets its market segments, outperforming its competitors on criterion 1 .

In terms of market coverage of segments covered, Manufacturer A leads the overall product offering. Manufacturer B leads in terms of the number of covered segments within a single product family.

Figure 6 shows a real-world example of a perception map for the modern wide-body twinengine segment excluding discontinued aircraft (Boeing 767, Airbus A330ceo (200/300) and those in the design phase (for example, CR929). Boeing 777, which are being replaced by the Boeing $777 \mathrm{x}$, are also not considered.

As we can see on the perception map, A330900, A350-900/1000 and 787-9 are in trend. They are the most in-demand at the moment in the selected segment, with the largest number of orders placed on them. 787-8/10 air- craft are less in demand, but increase the market coverage within the family. The situation is similar with A330-800 aircraft. Demand for them is low, but they expand the family's ability to capture the market. The $777 \mathrm{x}$ family (7778/9) aircraft are more spacious and noticeably different in other characteristics, so they are not generally considered direct competitors to the above aircraft. However, on the perception map, the increased capacity can be presented as an advantage.

\subsection{Digital simulation of product development}

Figure 7 schematically shows stage 4 , which involves multivariate marketing modeling of the creation and development of the product, taking into account the selected position based on the data obtained in the first and second 


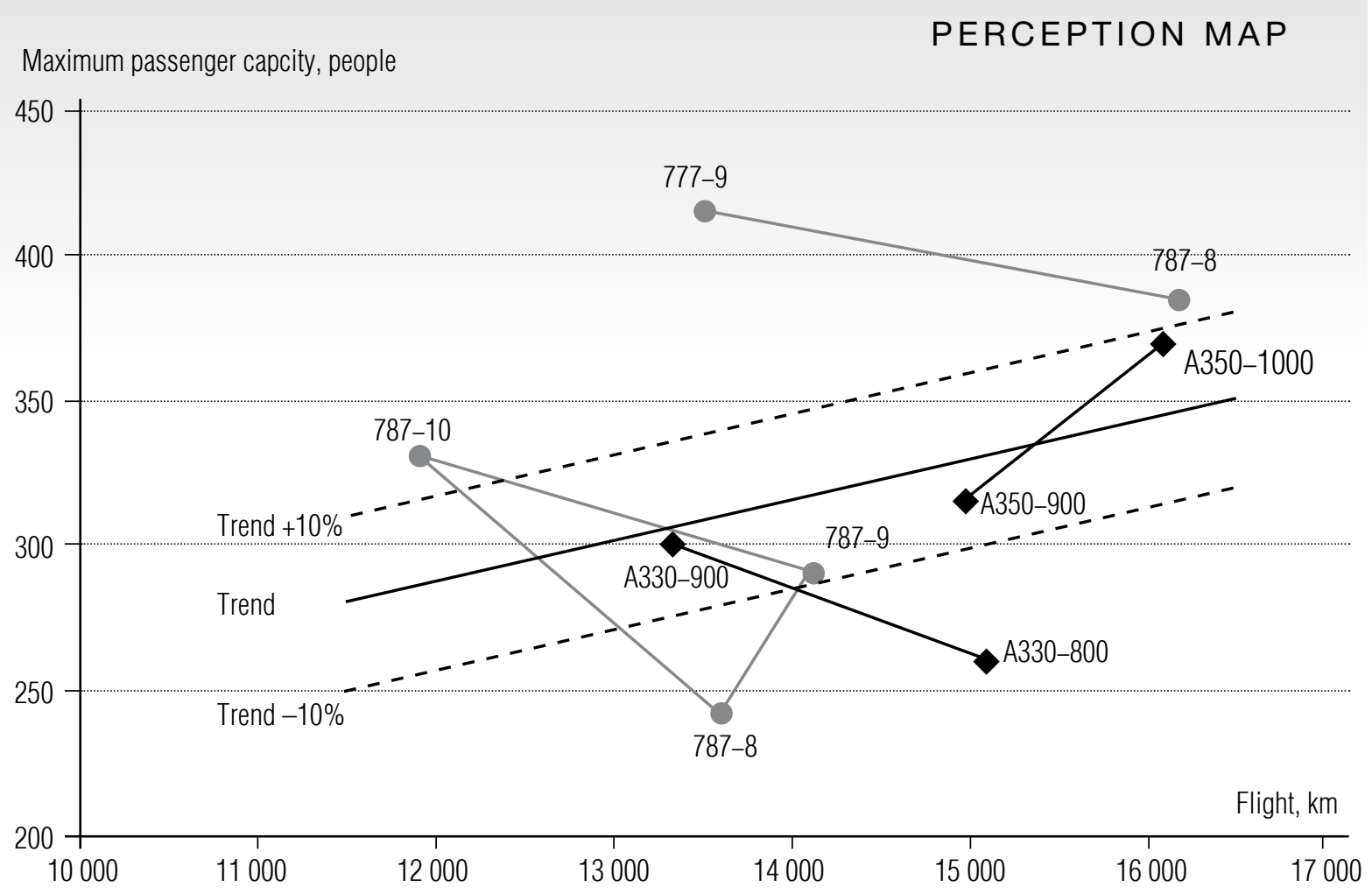

Fig. 6. Example of a perception map for Airbus and Boeing aircraft

stages. The final result of the stage is a business plan of the project to create a new product, which takes into account the following:

- ales plan made taking into account the modeling of consumer behavior in the projected long-term conditions within the formed marketing positioning of the product. It is necessary to take into account the different types of business models of airlines, as described in the work by Cook [14];

- results of modeling the creation and production of the product based on market requirements that provide a competitive advantage;

- results of modeling the operation of the product at all stages of the life cycle based on the evaluation of the economics of airlines - target potential consumers of the product. As Riordan [15] noted, the duration of the life cycle of the aircraft as a product is an important feature that determines the specifics of organizational processes. The results obtained are taken into account when modeling consumer behavior.

Stage 5 in continuation of stage 4 involves assessing the cost-effectiveness of implementing the chosen position of the new aircraft as a part of business planning. To this end, a base of business plan options necessary for further decision-making is formed.

Stage 6 involves a decision to approve or modify the position. In the second case, a return to stage 3 is required, and, if necessary, to stage 1 or 2 for additional research on the external environment, customer segmentation and competitive analysis. 


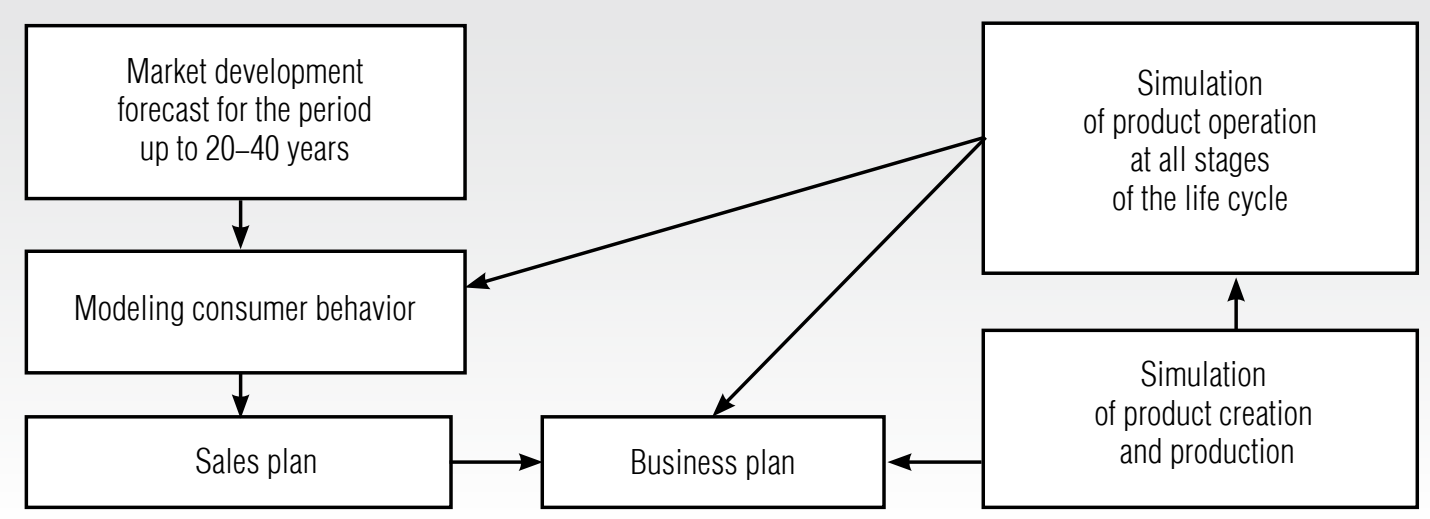

Fig. 7. Digital modeling of marketing management of product development at all stages of the life cycle

\section{Discussion of marketing positioning}

Marketing positioning of passenger commercial aircraft by the criteria pair "flight range passenger capacity" that was described in previous paragraph illustrates the possibilities of demand management in a fiercely competitive environment. In this case, even not good enough positions of the product, presented on the map of perception, can be used by the manufacturer as an advantage, for example, in the development of pricing policy, providing a better price-quality ratio. The issue of pricing is considered in detail by Kalugina [16].

It is important to note that during the construction of perception maps one should not always strive to achieve the maximum indicators according to the chosen positioning criteria. It is necessary to meet the needs of the chosen target segment. In aviation, there are many examples of targeting a narrow market segment. For example, when segmenting customers by geography, as Czinkota [17] discovered, E-Jets, Canadair Regional Jet, Mitsubishi Regional Jet on the United States market and ARJ21 and SSJ-100 on national markets were successfully positioned. In line with the type of business model, the 737 and
A320 families are positioned for low-cost airlines, while 747 and A330 wide-body jets are positioned for charter airlines. As Clark [18] wrote, the A380 is intended for use by airlines in the Middle East and Asia to serve flights between these regions on lines with very high traffic. The 747-400D is intended for shorthaul flights on high-traffic lines in the Japanese market. It should be noted that other methods of positioning Airbus and Boeing aircraft are used in parallel with this method. The method of positioning based on building of perception maps with criteria which reflect specific requests of target segments to the aircraft is also used by airlines on the related market of air transportation as mentioned by Malaval [19].

\section{Conclusion}

This article deals with the issues of modeling marketing positioning in the process of creating and producing such high-tech, science-intensive products as civil aircraft. The emphasis is placed on the procedural component, which is less represented in theoretical developments and scientific works. At the same time, the procedure of marketing positioning is reflected in the framework of modeling the innovative pro- 
cess of creating aviation equipment and its operation at all stages of the life cycle, which characterizes the novelty of the very statement of the management problem.

In developing the procedure according to the formulated principles, six main stages aimed at market research and positioning of the product offer of the aviation industry enterprise were identified.

In connection with the specifics of civil aircraft as a commodity, it was proposed to study not only the market of aircraft, but also the related market of air transportation, which depends on the condition and development of the demand for aircraft. In the allocation of target segments, it is proposed to analyze the correlation segmentation of these markets, which is not typical of the markets B2C, but necessary for most industrial markets.
The peculiarity of the procedure is also the proposal of the stage of assessment of the effectiveness of implementing positioning of a new product within the framework of business planning.

The question of information support of positioning, including the definition of categories of data necessary for decision-making, information sources, as well as methods of collection and processing of information, is aimed at the possibility of implementing the proposed procedure in a particular environment.

The significance of the results of the research is determined by the development of the concept of marketing positioning. Within the limits of the classical methodical approach to definition of a position of the goods, the procedure offered here reflects the specificity of the market of civil planes and expands possibilities of branch marketing.

\section{References}

1. Scheinberg R. (2017) The commercial aircraft finance handbook. London: Routledge. DOI: https://doi.org/10.4324/9780203713303.

2. Spreen W.E. (2016) Marketing in the international aerospace industry. London: Routledge. DOI: https://doi.org/10.4324/9781315249681.

3. Vasigh B., Gorjidooz J. (2016) Engineering economics for aviation and aerospace. London: Taylor \& Francis. DOI: https://doi.org/10.4324/9781315644257.

4. Zaripov R.N., Murakaev I.M., Novikov S.V., Ryapukhin A.V. (2020) Corporate structure for innovative enterprises. Russian Engineering Research, vol. 40, no 2, pp. 137-139. DOI:10.3103/S1068798X20020239.

5. Tikhonov G.V., Lavrova L.A., Kolosova V.V., Zemlyanskaya N.B., Kazakova N.V. (2020) Marketing as an effective control of progressive innovations. TEM Journal, vol. 9, no 3, p. 1094. DOI: https://doi.org/10.34069/AI/2021.41.05.18.

6. Ryapukhin A.V., Kabakov V.V., Zaripov R.N. (2019) Risk management of multimodular multi-agent system for creating science-intensive high-tech products. Espacios, vol. 40, no 34, p. 19. DOI: http://dx.doi.org/10.21533/pen.v9i4.2388.

7. Hooley G.J., Piercy N., Nicoulaud B. (2008) Marketing strategy and competitive positioning. New York: Pearson Education.

8. Embraer S.A., the Official Web site (2021) Media and downloads. Available at: https://www.embraercommercialaviation.com/media-downloads/ (accessed 01 April 2021)

9. Bombardier Inc., the Official Web site (2021) Airport emergency publications. Available at: https://u.to/7JCEGg (accessed 01.04.2021). 
10. Airbus SE, the Official Web site (2021) Aircraft characteristics, airport operations and tech data. Available at: https://www.airbus.com/aircraft/support-services/airport-operations-and-technical-data/ aircraft-characteristics.html (accessed 01.04.2021).

11. The Boeing Company, the Official Web site (2021) Airplane characteristics for airport planning. Available at: https://www.boeing.com/commercial/airports/plan_manuals.page (accessed 01.04.2021).

12. Guzhva V. S., Raghavan S., D’Agostino D. J. (2018) Aircraft leasing and financing: Tools for success in international aircraft acquisition and management. Amsterdam: Elsevier.

13. Kalugina G.A. (2018) Civil passenger aircraft prices determination features. Economics and management in mechanical engineering, no 3, pp. 30-34 (in Russian).

14. Cook G.N., Billig B. (2017) Airline operations and management. Management textbook. London: Routledge. DOI: https://doi.org/10.4324/9781315299594.

15. Riordan D., Kundu A. K., Price M. A. (2016) Theory and practice of aircraft performance. New York: John Wiley \& Sons Limited. DOI: https://doi.org/10.1017/S0001924000091636.

16. Kalugina G.A. (2013) Marketing research of aviation-industrial enterprises in the process of an aircraft family development. MAI Works, no 69 (in Russian).

17. Czinkota M.R., Ronkainen I.A. (2013) International marketing. 10th edition. Boston, MA: Cengage Learning. DOI: https://doi.org/10.1080/08975931003644630.

18. Clark P. (2017) Buying the big jets - fleet planning for airlines. London: Routledge. DOI: https://doi.org/10.4324/9781315195780.

19. Malaval P., Benaroya C., Aflalo J. (2013) Aerospace marketing management: A handbook for the entire value chain. Berlin: Springer Science \& Business Media. DOI: http://dx.doi.org/10.1007/978-3-319-01354-1.

\section{About the authors}

\section{Galina A. Kalugina}

Ph.D. (Econ.);

Associate Professor, Department of Management and Marketing of High-tech Industries, Moscow Aviation Institute (National Research University), 4, Volokolamskoe Shosse, Moscow 125993, Russia;

E-mail: kalugina@gmail.com

ORCID: 0000-0002-2085-8851

\section{Anatoly V. Ryapukhin}

Senior Lecturer, Department of Industrial Economics, Moscow Aviation Institute (National Research University), 4, Volokolamskoe Shosse, Moscow 125993, Russia;

E-mail: anatoliiruapukhin@yandex.ru

ORCID: 0000-0002-2208-6875 